\title{
Experiences of fatherhood among men who were sexually abused in childhood
}

\author{
Jean O’Brien ${ }^{\mathrm{a}, \mathrm{b}}$, Mary Creaner ${ }^{\mathrm{a}}$, Elizabeth Nixon ${ }^{\mathrm{a}} *$ \\ ${ }^{a}$ School of Psychology, Trinity College Dublin, Ireland \\ ${ }^{\mathrm{b}}$ Health Service Executive, Cork, Ireland
}

\section{A R T I C L E I N F O}

\section{Keywords:}

Fatherhood

Sexual abuse

Trauma

Interpretative phenomenological analysis

\begin{abstract}
A B S T R A C T
Background: Fatherhood is a complex psychological process, which is shaped at a profound level by reflections on past childhood memories and parenting experienced in childhood. Fathers who were sexually abused in childhood may experience particular challenges for their fathering identity and parenting role.

Objective: This qualitative study explored the experiences of fatherhood for men who were sexually abused in childhood and how they perceived themselves in the fathering role.

Participants and Setting: Eleven participants were recruited to the study from three therapy services for adult survivors of abuse in the Republic of Ireland.

Methods: Data collection comprised face to face semi-structured interviews, which were audio recorded and subsequently transcribed verbatim. Data analysis drew on Interpretative Phenomenological Analysis and two superordinate themes with associated subthemes were identified.

Results: Participants' experience of childhood sexual abuse provided a lens through which they experienced fatherhood and themselves in a fathering role. Fatherhood influenced participants to confront unintegrated aspects of the trauma they experienced in childhood, which manifested in hypervigilance with regard to their children's safety and doubt that they were good enough fathers. However, fatherhood also offered an opportunity to heal. This occurred through striving to provide a better father-child relationship and through connection in restorative relationships, including the therapeutic relationship.

Conclusion: Fatherhood was seen as a potential resource for positive change and can influence long held internal working models of the self and others.
\end{abstract}

\section{Introduction}

Becoming and being a father has been described as a complex psychological process, one which is shaped at a profound level by reflections on past childhood memories and parenting experienced in childhood (Madsen, 2009; Marsiglio \& Hutchinson, 2002). For fathers who were sexually abused in childhood, reflecting upon these previous experiences may represent an additional challenge for their fathering identity and parenting role (Lainsbury, 1999). The aim of the current study was to explore the experiences of fatherhood among men who were sexually abused in childhood.

Substantial evidence attests to the short- and long-term deleterious impact of childhood sexual abuse (CSA) on victims (Trickett,

\footnotetext{
* Corresponding author.

E-mail address: enixon@tcd.ie (E. Nixon).
} 
Noll, \& Putnam, 2011; Hillberg, Hamilton-Giachritsis, \& Dixon, 2011). Some studies have indicated worse outcomes occur when the abuse is perpetrated by a family member, particularly a father or father figure (Tremblay, Hébert, \& Piché, 1999) or when the abuse is more frequent, invasive or of a longer duration (Trickett, Reiffman, Horowitz, \& Putnam, 1997). However, several reviews have indicated considerable inconsistencies in the associations between characteristics of the abuse experience and subsequent outcomes (Paolucci, Genius, \& Violato, 2001; Hillberg et al., 2011). In addition, the links between outcomes for the victim and involvement of child protection services and its resultant outcome for the perpetrator have not been well established, although parental support of the victim has emerged as a key predictor of outcomes (Elliott \& Carnes, 2001; Wamser-Nanny, 2017).

The negative effects of CSA can carry into the next generation, as CSA has been associated with many difficulties for victims who subsequently become parents, including lower parental sense of competence, greater parenting stress, unrealistically high expectations of themselves as parents, fear that they may sexually abuse their own children, and over-protection of their children (Denov, 2004; Nelson, 2009). A number of mechanisms has been proposed to explain how the experience of CSA may relate to one's parenting later in life. Exposure to childhood trauma may challenge the individual's capacity to establish a cohesive personality, which has the potential to impact the process of integration among memories, emotional states, and physical experiences (Sanderson, 2006). This lack of integration may then present significant challenges throughout the parenting experience (Koren-Karie, Oppenheim, \& GetzlerYosel, 2008). The dynamics of CSA, particularly when perpetrated by an attachment figure or an adult deemed to be trustworthy, have the potential to negatively affect the experience of attachment and how a person relates to oneself and others (Sanderson, 2006). For example, an abusive parent is by definition not mirroring empathic responses to the child and consequently the child may not internalize empathic responses to the self (Sanderson, 2006). Similarly, Thomas (2005) suggested that children who have been sexually abused do not form internal working models of an effective protector, with the result that they have difficulty defending themselves against "interpersonal aggression and internal self-criticism" (p. 20). Moreover, children who are living in threatening environments are likely to become preoccupied with protecting themselves and less likely to develop interests and explore their sense of identity (Barton, Gonzalez, \& Tomilson, 2010).

Research on the intergenerational transmission of attachment patterns shows that unresolved trauma in one generation may be associated with insecure attachment patterns in the next (Lyons-Ruth \& Block, 1996). From an attachment perspective, resolution involves revision of the person's internal working models so that trauma has been integrated into the individual's mind and narrative, such that they are able to orientate to the present (Koren-Karie et al., 2008). Where resolution does not occur, the trauma is not integrated into the person's internal working model (Main \& Hesse, 1990), and multiple conflicting representational models exist (Lyons-Ruth \& Block, 1996). Unresolved trauma is indexed by mental disorganisation around the trauma, such as for example, lapses in reasoning while talking about the abuse, or denial of the occurrence of the abuse experience (Main, Hesse, \& Goldwyn, 2008).

Unresolved trauma may impact on the parent's ability to provide safety, comfort, and security to their own children due to a lack of reflective functioning (Koren-Karie et al., 2008). Reflective functioning refers to a parent's capacity to comprehend the distinct, independent, developing mind of the child, so that the child in turn develops a sense of their own mind and the ability to regulate their affect (Fonagy, Gergely, Jurist, \& Target, 2002). When a parent's own traumatic experiences have not been resolved, they are not adequately able to make sense of their childs' emotions and internal feelings. The emotional dependency of a child may evoke memories of a parent's childhood experiences (Lyons-Ruth \& Block, 1996; Slade \& Cohen, 1996). Therefore, parents who were abused as children may have difficulties responding to their children's attachment needs due to the evocation of painful memories related to violations of trust with their own attachment figure as well as associated feelings of fear, powerlessness and anger (Lyons-Ruth \& Spielman, 2004). Berthelot et al. (2015) found that mothers with childhood experiences of abuse and neglect struggled to respond to their infants' attachment needs and Babcock Fenerci and DePrince (2018) similarly found that maternal trauma-related cognitions were linked to dysfunction in the mother-child relationship.

The majority of studies carried out on the impacts of CSA on later parenting have focused on women and motherhood (Cohen, 1995; Fitzgerald, Shipman, Jackson, McMahon, \& Hanley, 2005). Much less is known about how a history of CSA influences the experiences of fathers and their fathering behaviour (Lisak, 1995, 2001; Crome, 2006), a gap which the current study sought to address. As gender can influence the ways in which the person is impacted by CSA, the experience of parenting in the context of CSA may be different for men than it is for women (Lisak, 1995; Crome, 2006). Additionally, masculinity norms in society can lead men to deny feeling vulnerable, and less likely to disclose their abuse, which may affect help seeking and the recovery process (Lisak, 1995, 2001; Rapsey, Campbell, Clearwater, \& Patterson, 2017). Therefore, men who have experienced CSA and who are or plan to be fathers may face challenges that are quite distinct from those reported by women or mothers.

As CSA has previously been found to negatively affect parenting among mothers (Fitzgerald et al., 2005; Zvara, Mills-Koonce, Carmody, \& Cox, 2015), it is important to expand the field to consider how fathering is shaped by the experience of CSA. It is also important for research to confront cultural and social stereotypes associated with men and their experiences of parenting. Support for fathers who have experienced CSA, like mothers, is a very real need, particularly as the potential impacts can obstruct the otherwise enjoyable experience of parenting, and thus may continue to impact the father-child dyad. As noted by Price-Robertson (2012, p. 136) fatherhood may be "a catalyst for the resurfacing of trauma", although it may also be experienced as a restorative and healing experience for male survivors of CSA (Wark \& Vis, 2018).

To date, only a small number of qualitative studies have explored the experiences of men with a history of CSA (Denov, 2004; Dorahy \& Clearwater, 2012; Etherington, 1995; Kia-Keating, Grossman, Sorsoli, \& Epstein, 2005; Nelson, 2009; Rapsey et al., 2017). None of these studies was specifically focused on fatherhood or parenting among these men, and only minorities of their samples of men were fathers. Thus, to our knowledge, the present study is the first of its kind and addresses an important gap in the research literature. In only four studies did fatherhood emerge as part of broader discussion on the impact of CSA. Key findings were that men either avoided being with their children or did not want to have children and that men were afraid that they would abuse their own 
children (Denov, 2004; Etherington, 1995; Kia-Keating et al., 2005; Nelson, 2009). In light of the dearth of research on fatherhood among men who have experienced sexual abuse in childhood, the current study is exploratory with no a priori hypotheses. The aim of the study was to explore how fathers who were sexually abused in childhood experience fatherhood and themselves in the fathering role.

\section{Method}

The current study adopted an Interpretative Phenomenological approach (IPA; Smith, Flowers, \& Larkin, 2012) to underpin the exploration of nuanced experiences of fatherhood among men who were sexually abused in their childhood. An IPA approach is of use when one is concerned with individuals' experiences of a phenomenon which was congruent with the area of inquiry.

\subsection{Participants}

Purposive sampling was used to recruit a homogenous group of fathers who had experienced CSA in order to provide for a rich, indepth inquiry. Participants were clients from three different counseling organisations in the Republic of Ireland providing counseling services to adult survivors of childhood abuse. The inclusion criteria for participation were to have experienced CSA prior to 18 years of age by a person at least five years their senior and who was in a position to provide care towards them; and having at least one child aged younger than 25 years. In addition, the participant needed to be a current or former client of a counseling service and had an established relationship with their therapist ( $>8$ sessions). Although previous research has found that participating in research on sexual victimisation can be beneficial for those with sexual victimisation experiences (Edwards, Kearns, Calhoun, \& Gidycz, 2009), conditions of receiving ethical approval for the current study were that participants had access to their therapist following the research interview to debrief if necessary. In addition, as part of a risk assessment protocol, in order to protect those who were perceived to be especially vulnerable clients were not invited to participate in the research if they presented with suicidal ideation or were at risk of suicide, if they were abusing alcohol or drugs at the time of the study, or where it was the therapists' opinion that engaging in the research study may impact negatively on a client or their therapy. It is acknowledged that the criteria for participation in the research has likely resulted in the exclusion of survivors who may be struggling with fatherhood the most and that the generalizability of our findings has been limited by the homogenous sample that does not fully represent fathers who have experienced sexual abuse during childhood.

Data for this study were derived from in-depth semi-structured face to face interviews with 11 fathers who had experienced sexual abuse during childhood. All 11 participants were white and Irish and ages ranged from 36 to 64 years $(\mathrm{M}=45$ years, SD $=9.02)$. At the time of the interview, 6 of the participants were employed, 4 were unemployed and 1 participant was retired from employment. The men had between 1 and 4 children ranging from 7 months to 37 years $(\mathrm{M}=11.41$ years; SD $=8.78)$. Of the 11 participants, 4 had all of their children living with them at the time of the interview, 3 lived with some of their children, and 4 were not resident with their children, but did have contact. Six of the participants were married at the time of the interview; 2 were never married but were in a relationship and living with the mother of their children while 3 participants were never married and had separated from the long-term relationship in which they had children. Of these 3 participants, 2 of them were in new relationships. Six of the participants reported experiencing extrafamilial CSA and 4 reported experiencing intrafamilial CSA. One of the participants reported experiencing both intrafamilial and extrafamilial CSA. Each of the 11 participants did not disclose the CSA until they reached adulthood and 9 disclosed only after they became fathers. The length of time that the participants had attended counseling services ranged from 3 months to 7 years $(M=2.8$ years, $S D=2.11)$.

\subsection{Procedure}

Ethical approval to conduct the study was granted by the authors' university. Three counseling services in the Republic of Ireland agreed to host the study, assist with recruitment and provide clinical support to the participants after the interview, if required. If clients were deemed eligible to participate by their therapist and met the inclusion criteria, the therapist provided them with an information pack detailing the nature and procedures of the study. Where clients consented to participate, an interview was arranged with the lead author.

Interviews occurred in the relevant counseling centre and were conducted by the first author, audio recorded and lasted up to $90 \mathrm{~min}$ (mean time of $60 \mathrm{~min}$ ). Participants were assured that their anonymity would be protected and that information was confidential within statutory limits (e.g., risk to self or others). Debriefing was provided at the end of the interview and clinical support was available to participants, if required. Pseudonyms were used in the write up of the study to protect the anonymity of the participants and the people they discussed during the interview.

The interview schedule comprised open-ended questions including 4 broad questions about childhood experiences (e.g., describe your relationship with your parents as a young child, starting as far back as you can remember; would you be able to tell me about the difficult things that may have happened to you as a child?), 7 questions about the experiences of fatherhood (how would you describe yourself as a father?; what aspects of parenting do you find most difficult?) and 5 questions about resources in the fathering role (how would you describe your relationship with your child's mother?; are there aspects of the parenting role she encourages/discourages?). Probes were used to gain a clearer and deeper understanding of the participants' answers. Contextual demographic information was collected via questionnaire prior to the interview. 


\subsection{Data analysis}

Data analysis was conducted in line with steps outlined by Smith et al. (2012) for Interpretive Phenomenological Analysis. Following verbatim transcription of each interview, the first author read each transcript multiple times, recorded initial reactions and noted anything that was evocative or significant about the participant's words. For example, one participant stated: "Well I remember when me older young fella was a baby and I was changing his nappy I felt uncomfortable, you know touching him around there and then me niece when I had her staying over with me... I was thinking to meself do they trust me with her...so I started doubting myself". Initial notations of 'discomfort', 'self-doubt' and 'fear of judgement from others' were reported alongside this quotation. Upon completion of this notation or coding process with the entire transcript, the researcher documented associations among these codes and emerging themes were identified; such as "The Doubting Self". This transformation of initial notes into themes was continued through the entire transcript. This process was repeated in turn for each of the 11 transcripts.

In order to connect themes identified within each transcript, themes that clustered together and/or were identified as superordinate concepts were noted and collated in a table. To aid this process, participant phrases were listed in support of the core concepts identified. For example, the theme "The Detached Self", was derived from codes pertaining to avoidance of being physically or emotionally present with their children, as exemplified by this quotation: "[Family, my children] is something I've withdrawn from, it's too intimate and it's too close and it's too painful". "The Vigilant Self", emerged from codes about fear and an over-riding need to protect their children from harm, and is illustrated by the quotation "I still have the fear, always the fear of something happening". These themes in turn were brought together into a superordinate theme "Confronting the Tormented Self through Fatherhood" which reflected that having children triggered various aspects of the fathers' traumatic past experiences.

Themes that represented most of the participants' accounts by richness, poignancy and prevalence across cases were prioritized. As the process continued for other transcripts convergences and divergences in the data were respected, highlighting ways in which accounts from participants were similar but also different, thereby ensuring that there was a place in the analysis for distinctive voices and variations of themes (Smith et al., 2012).

The analysis was initially undertaken by the first author. In order to enhance rigor and trustworthiness of the analysis, transcript excerpts, codes, and emerging themes were provided to an independent peer and the two co-authors. Discrepancies in interpretations were discussed and the conceptualisation of the codes, sub-themes, and themes were refined in order to reach consensus on how best to represent the data. These discussions about the emerging concepts continued throughout the analysis process.

\section{Results}

The analysis yielded two superordinate themes and five related subordinate themes, which encompassed participants' experiences of fatherhood in light of childhood sexual abuse, as outlined in Table 1. There were no discernible associations between men's experiences of fatherhood and their marital status or whether their abuse experience was intra- or extra-familial. Participants' experiences of CSA seemed to provide a lens through which they viewed themselves as fathers. Fatherhood seemed to both trigger unintegrated aspects of their own traumatic childhoods and offer the opportunity to heal from these experiences. In conveying the participants' own words, pseudonyms are used.

\subsection{Confronting the Tormented Self in Fatherhood: "It opened up a wound that was already there"}

This superordinate theme was identified as prominent in the participants' accounts of their experiences of fatherhood and the impacts of CSA on their fathering role. Becoming a father seemed to be a catalyst for triggering various aspects of their traumatic pasts and this manifested in varying ways. As a means of self-protection, the participants had endeavoured from an early age to block out their experiences of CSA. However, having children provided a mirror to their past where feelings of torment had to be confronted. The themes of vigilance, feeling doubtful of themselves, and unaccepted as fathers by self and others, and emotionally and physically detaching from their families all emerged as prominent in their accounts of confronting the self in fatherhood.

\subsubsection{The hypervigilant self}

The subordinate theme of "The Hypervigilant Self" reflected the participants' perceptions of the world as a dangerous place, where adults were perceived as potentially predatory. Many of the participants described being tormented by fear that their children would be harmed or abused by others if out of their sight. Many linked their over-protection for their children and mistrust of adults

Table 1

Superordinate and subordinate themes.

\begin{tabular}{lll}
\hline Superordinate Theme & Subordinate Theme & Illustrative Verbatim \\
\hline Confronting the Tormented Self & The hypervigilant self & I still have the fear, always the fear of...something happening. \\
& The doubting self & I could be judged...as an abuser \\
I just go around in a haze & The detached self & When you hold your children in your arms that helps you to \\
change & Wanting to provide a better father-child & I'm allowing myself to reach out \\
& Reconnecting to the Self through others &
\end{tabular}


as stemming from their abusive childhoods. As Raymond described:

Like there are some things that will kind of trigger that ... overprotectiveness, like (child's name) just started school, that was very stressful...you know I'm not gonna be there, it's a new environment, they're gonna know no-one... So I'm just always, there was always that kind of, you know I couldn't trust 'em before, so how can I trust 'em now.

Others spoke of how their experiences of CSA led them to expecting that something negative would also happen to their children:

If the school phones I panic, if she goes to her friends I panic, what goes through my mind? The same thing that happened to me, somebody's after doing it to them, I do, I panic. I still have the fear, always the fear of them going out and something happening [Patrick]

\subsubsection{The doubtful self}

The participants' self-doubt as fathers and also their anxiety of being judged as being capable of abusing their own children was captured in the subtheme of "The Doubtful Self". Stemming from childhood, the participants spoke about the fear of judgement, shame and self-blame they felt at the time of the sexual abuse which led them to withdraw from others and actively withhold their experience through non-disclosure. The participants described feeling more aware and more doubtful when they compared themselves to parents with no such abusive histories:

...people say that people who got abused tend to be abusers and I was thinking, especially with me first young fella when I was changing his nappy or anything like that. Like I wouldn't let, when I was in the shower and he'd come in when he was only a baby, I'd pull the curtain and say get out, don't be looking [Mason]

\subsubsection{The detached self}

For the majority of the participants, the trauma that they held from childhood often led to detachment and a struggle to be emotionally present with their own children, as expressed in the subtheme of "The Detached Self". Participants spoke of avoiding emotional connection with others in their own childhoods as a means of self-protection from feelings of intense shame and how this impacted on connection with their children. As Chris reported: "It is easier for me not to be in the presence of others, including my children and I'm aware of that...that's difficult...it's something that I've withdrawn from, it's too intimate and it's too close and it's too painful". For others, being with their children sometimes triggered the trauma that they experienced as a child which made it difficult to be present with their children. Mark recounted:

I found the relating to the children and having to be present with the children very challenging...so it's almost trying to be the adult when your own child is screaming out sometimes within yourself and a lot I found very, very challenging.

For others there was a sense that their unresolved childhood trauma and detachment impacted their enjoyment of the parenting process. For example, some of them described how they would be more irritable at home because of the emotional torment they were experiencing.

\subsection{Restoring the Self through Fatherhood: "When you hold your children in your arms that helps you to change"}

This superordinate theme was prominent in all of the participants' accounts of wanting to compensate for their traumatized childhoods by doing their utmost as fathers, with particular emphasis on providing their children with a better experience of the father-child relationship. Becoming a father seemed to offer these men the opportunity to begin to heal from their childhood experiences and to integrate them into their identities. It reflected a process of seeking to connect with others through more supportive, compassionate and restorative relationships. The participants described how changing self-perceptions was an emerging process for them in their development as a father.

\subsubsection{Wanting to provide a better father-child relationship}

In the subordinate theme, "Wanting to provide a better father-child relationship" many of the participants could not identify a loving attachment figure in childhood and all described what seemed like an insecure attachment to at least one parent. However, the participants' words evoked a sense of healing through their parenting and through a commitment to providing better relationships with their children. Many participants appeared to gain comfort through knowing, on a profound level, what was important for them as fathers and in the hope that their children would never feel as hurt or isolated as they did as children. Although variations emerged, the majority of participants discussed striving to provide emotional support, availability, open communication, flexible parenting strategies, love and affection. They placed strong emphasis on establishing an open and communicative relationship where their children could approach them for support. As Mason articulated:

I tell me kids that I love them all the time and I hug them all the time. I try to break the cycle whereas I didn't get as much when I was a child. I give my kids a different experience you know.

\subsubsection{Reconnecting to the self}

Despite the layers of a traumatic past that had to be worked though, each participant appeared to be engaging in a process of integrating their childhood experiences into their identities as men and as fathers as reflected in the subtheme "Reconnecting to the 
Self". Participants appeared to be doing this through a process of turning outward and connecting through more supportive and compassionate relationships, including the father-child relationship, the counseling relationship and relationships with their partners. These relationships seemed to support them to change long-held internal working models of self and others and to find out who they are as fathers, and as men. Many participants spoke about the restorative nature of the father-child relationship and how this was helping them to move forward with their lives.

When I was single I didn't care about anyone around me, but as a father when you hold your children in your arms that helps you to change. You're feeding your own children... and they are crying for your help, for that feed, which I was as well, I was crying for that feed. That makes you feel capable and understanding, that they are yours, they're part of your life. [Ken]

Brendan spoke poignantly about how his love for his son and their relationship stopped him from ending his life, which ultimately led him to seek support through counseling:

It just has an effect on every part of your life but I understand now and I enjoy every minute and every second that I do spend with my child now even more because I understand how close I was to not being here at all.

All of the participants spoke about how the counseling process helped them to heal past wounds and thus feel better equipped to cope with the challenges of fatherhood. Furthermore, developing insight through counseling appeared to have alleviated the weight of shame experienced by many of these men, as reflected by Brendan: "the way my head was before I got the counseling, like I am a completely different person and I feel completely different now than I did then. I found it very helpful, kinda life changing". Mark also described how counseling had helped him to process many developmental issues, and to integrate his childhood experiences, which he felt helped him to be a better father:

It has helped me go through my own developmental stage you know, it has helped me go through child issues meself, work through attachment issues, and becoming aware of that, it has helped me, freed me up, or helped me look at me own parental skills.

Fatherhood appeared to be a potentially restorative process and they seemed to be healing through reaching out in the fatherchild relationship, romantic relationships, and through self-discovery in the counseling relationship.

\section{Discussion}

The current study explored the experiences of fatherhood among 11 fathers who had experienced childhood sexual abuse. The findings supported the tenets of attachment theory, which posits that traumatic experiences in childhood, especially if they have not been appropriately resolved and integrated into one's internal working models, can cast a shadow on the persons' subsequent relationships, including relationships with their children (Bowlby, 1973; Main \& Hesse, 1990; Solomon \& George, 1996). Experiences of being sexually abused by someone in a position of care, or of caregivers failing to be available for support or protection, appeared to have left participants with a wounded sense of self and a perception of self as unlovable and unworthy in relation to others, and as a father (Bretherton, 1990; Cohen, 1995).

Experiencing CSA also led to feelings of shame and self-doubt for the participants and intruded upon their enjoyment of the fathering process. However, the current study also supported research showing that internal working models are not permanent and can change through significant life experiences and restorative relationships (Bowlby, 1973; Thomas, 2005). The experience of having children seemed to trigger painful memories from the participants' pasts and confronted them with unresolved aspects of their childhood trauma. Notably, the majority of the participants did not engage in counseling until after they became fathers. Hence, as reflected in the literature, becoming a father can act as a catalyst for the activation of intense emotional experiences associated with past trauma (Lainsbury, 1999; Maker \& Buttenheim, 2000; Price-Robertson, 2012), which in turn may be a motivation for helpseeking and recovery in order to become a better father. Overall, the results suggest that the experience of fatherhood may be a significant factor that contributes to survivors' healing (Wark \& Vis, 2018).

\subsection{The enduring burden of CSA on fathers}

Participants in the current study reported feelings of anxiety, self-doubt, anger, powerlessness, guilt, and shame as they experienced themselves as fathers. Influenced by internal representations of past attachment relationships that were abusive (Cook, 2000), the world was seen as an unsafe place with others viewed as unreliable, untrustworthy, and dangerous (Main, Kaplan, \& Cassidy, 1985). This, along with a perceived duty to compensate for the failures of their own caregivers, contributed to hypervigilance and overprotection of their children, characteristic of CSA survivors (Etherington, 1995; Denov, 2004; Nelson, 2009) and caused a great deal of strain in their lives and family relationships. Concurrently, participants reported acute awareness of the "victim-to-offender discourse" (Price-Robertson, 2012, p. 133) and associated stigma (Wark \& Vis, 2018), as they feared that they and others would perceive them as being capable of sexual abuse. Many of the participants expressed confusion at some stage during the parenting process about what constituted normal and appropriate paternal behaviour. These participants reported having refrained from, or felt uncomfortable when, engaged in intimate parenting activities such as nappy changing, bathing or being in a room on their own with their children. Consistent with other studies, this finding captures the sense of loss that can endure throughout the parenting process, whereby moments of connection in the father-child dyad are tainted both for the child and for the parent (Denov, 2004; Etherington, 1995; Kia-Keating et al., 2005; Lainsbury, 1999; Nelson, 2009; Walker, 1999). 
Generally, intense feelings of powerlessness and vulnerability conflict with traditional norms of masculinity and may contribute to delayed disclosure and help-seeking behavior among male CSA survivors (Lisak, 1995, 2001; Rapsey et al., 2017). While masculinity was not discussed explicitly in the current study, the participants described experiences whereby they had significant difficulty coming to terms with their experiences of CSA. This resulted in withdrawal from others, delayed disclosure until adulthood, internalising a sense of self as unworthy and unacceptable, and later feelings of inadequacy as parents, consistent with the literature (Fitzgerald et al., 2005; Sandberg, Feldhousen, \& Busby, 2012; Gill \& Tutty, 1999). Again, these feelings may have prevented the participants of the current study from help-seeking and engaging in supportive relationships that might have helped them to alter their internal working models of self (Lisak, 1995). Some refused to disclose the CSA to their families or minimized the impact that it had on them suggesting an enduring sense of shame and doubt about the reactions and perceptions of others.

Emotional connection with their children was often too painful or triggered participants' own traumatic childhood experiences resulting in episodes of detachment and withdrawal (e.g., emotional, physical, or through drug use or gambling) from their families. They described being able to detach very easily in order to contain overwhelming emotions blocking their capacity to connect emotionally with their partners and with their children, as also noted in the literature (Maker \& Buttenheim, 2000; Newcombe \& Locke, 2001; Kelly, Slade, \& Grienenberger, 2005; Koren-Karie et al., 2008). These findings resonate with key tenets of attachment theory: men who experienced CSA may react with fear or anger when they encounter vulnerability in their children because it evokes the "ghosts" of their own vulnerability (Lisak, 2001, p. 271). Crittenden (2006) proposed that adults with avoidant attachments may become emotionally overwhelmed or angry in cases where they cannot avoid emotion, as is likely the case when parenting a child, and when their defensive strategies break down. As suggested by Kelly et al. (2005), parents without the capacity for reflective functioning may take on a hostile or fearful and withdrawn role in relation to their children. Similarly, Hazen, McFarland, Jacobvitz, and Boyd-Soisson (2010) propose that fathers with avoidant attachments may not want to activate the attachment system with their children as it is too painful and hence, they may be more likely to withdraw emotionally from caregiving when feeling overwhelmed.

Despite the turmoil of the past, the findings of the current study revealed a strong wish on the part of the participants to provide their children with a better experience of the parent-child relationship. These findings support literature in the area whereby participants who had survived CSA described having children as a restorative experience and that they had made a decision to break any potential cycle of abuse with their own children (Nelson, 2009).

There has been a wealth of research suggesting that patterns of parenting tend to be transmitted across generations and that the caregiving system has its roots in childhood (Bowlby, 1982; Solomon \& George, 1996; Maker \& Buttenheim, 2000). However, the participants in the current study appeared to gain comfort in their efforts to ensure that their children would never be as hurt or feel as isolated as they did in childhood. This suggested that the experience of fatherhood contributed to transformation at a profound level and was perhaps changing long-held perceptions of self and others (Marsiglio \& Hutchinson, 2002; Nelson, 2009).

\subsection{Restorative relationships}

The father-child relationship, supportive partner relationships, and the counseling relationship appeared to be restorative relationships that helped change these men's representations of self and others, their experience of fatherhood, and of themselves within the role of father (Wark \& Vis, 2018). As most of the participants engaged in counseling only after they became fathers, their relationships with their children may have given them permission to acknowledge their own vulnerability in childhood and to care for themselves as adults (Lainsbury, 1999). Many of the participants spoke about the receipt of unconditional love from their children as being significant in re-working negative self-perceptions and in beginning to perceive themselves as "good enough" fathers.

Counseling and talk therapy is well acknowledged as a significant resource for CSA survivors with the interpersonal approach of the counselor and their ability to create trust and safety being significant predictors of outcomes (Chouliara et al., 2011; Parry \& Simpson, 2016; Rapsey et al., 2017). Consistent with the literature, the counseling relationship was perceived by many of the participants in the present study as helpful in terms of gaining insight into their past and integrating their trauma experiences into their identities. Through a supportive, trusting, and safe therapeutic relationship, they were able to address problematic parenting practices and to ease feelings of anxiety, doubt, and shame experienced in relation to the CSA and parenting. Participants frequently reported having benefited from both individual and group therapy, with many of them speaking about only coming to the realisation that they were not to blame for the CSA when they engaged in therapy. The findings also suggest that in order to reconnect to the self, the participants had to begin to let go of masculine ideologies, reach out to others for support, and to accept feelings of vulnerability, shame and fear (Lisak, 1995, 2001). The participants described how learning to connect with others facilitated their ability to connect with their children and to be more accepting of themselves within the fathering role. This also resonates with humanistic ideas around self-actualisation whereby individuals have an innate tendency to fulfil their utmost potential and will flourish when the necessary conditions (i.e., non-judgement, unconditional positive regard, and empathy) are sufficient in their environment (Rogers, 1961). This includes the availability of supportive relationships, which can help a person to integrate traumatic experiences and rebuild their relational capability (Joseph \& Linley, 2005; Wark \& Vis, 2018).

\subsection{Strengths and limitations}

The results of the current study offer a rich in-depth description of the experiences of 11 participants, from a hard to reach, marginalized population, in the hope that they provide insight for mental health professionals working with similar populations. Nonetheless, there is a number of significant limitations in the current study that need to be considered when evaluating the transferability of the current findings. Notably, the participants in the current study were a homogenous group of White, Irish fathers with a 
mean age of 45 years, who had all self-referred to therapy, and who had disclosed their CSA. Hence, there are limitations to transferability from this specific group to a larger population, for example, younger fathers, fathers from diverse ethnic groups, fathers who have not disclosed or fathers who have not sought counseling support. Furthermore, while the exclusion criteria of the study (e.g. participants who were actively suicidal; currently engaged in substance use) were established based on a risk assessment of recruiting a vulnerable population, the sample is not representative of fathers with a CSA history. However, we note that all participants discussed their motivation to participate in the current research in terms of wanting to share their experiences so that others might benefit, which in turn was empowering for them, a point consistent with the literature (Edwards et al., 2009; Etherington, 1995).

As was the case among the participants of the current study, many survivors have not experienced CSA in isolation with dysfunctional patterns of behaviour in the care system (e.g., neglect, domestic violence, parental substance use) being frequently reported (Romano, Moorman, Ressel, \& Lyons, 2019). Therefore, it is difficult to discern how other trauma experiences may have impacted upon parenting and the limitations of this are recognized. Similarly, understanding of how fathers perceive themselves in their role following CSA may be limited considering that there were no follow-up interviews at different stages of the fathering process. Finally, although empathic engagement and rapport building were goals for each of the interviews, social desirability may have been a factor in participants' responses (Ball, 2009). However, during the interviews participants did not appear reserved in their responses and they generally seemed to be candid and open. It is worth noting that the interviewer was a female researcher, and although the participants often cited that they were more comfortable talking to females, this may have influenced their responses.

\subsection{Implications and future directions}

Considering the unique psycho-social sequelae of CSA for men who subsequently become fathers, mental health professionals need to be aware of and especially sensitive to traditional norms of masculinity, related stigma, both from internalized stigma and fear of others' perceptions, and the prevalent "victim-offender" narrative in their work with this population. Clinicians also need to recognize that overtly addressing sexual abuse may be very difficult for men struggling against gender stereotypes and the need to provide a safe, non-pathologizing environment that enhances interpersonal trust and relational capability (Joseph \& Linley, 2005; Wark \& Vis, 2018; Chouliara et al., 2011; Parry \& Simpson, 2016; Rapsey et al., 2017).

The results suggest that neglecting the treatment needs of fathers who have experienced CSA has potentially far-reaching consequences for the family system, hence, there is a specific need to advocate for and promote the development of parenting education programmes and accessible support services for fathers who experienced childhood trauma. Such services may support men to learn about the importance of attachment, reflective functioning, child development, and new ways to respond to their children, thus enhancing the experience of fathering and reducing the potential for the intergenerational transmission of attachment patterns (Lyons-Ruth \& Block, 1996).

That all participants in the current study only disclosed their CSA after they were adults, with a majority only reporting after they became fathers, is indicative of the burden and stigma associated with CSA for fathers. Time to disclosure of CSA has been estimated to be in excess of 20 years for men (Easton, 2014), with such delays having adverse implications for their mental well-being (Romano et al., 2019), and more broadly, for child protection (McElvaney, 2015). Hence, future research, with a larger, more diverse sample is warranted to establish what facilitates and hinders disclosure with this population, and to identify the optimal conditions for earlier help-seeking behaviour. Finally, given their traumatic histories, it was clear that the participants in the current study were extremely resilient. Research into areas that support these fathers across different stages of the fathering process would help inform treatment and service provision in this context.

\subsection{Conclusion}

The current study aimed to explore the experiences of fatherhood and how they perceived themselves in the fathering role among men who were sexually abused in childhood. Results indicated that the fathering process resulted in participants being confronted with many painful memories associated with their past. They poignantly described their anxiety, self-doubt, and struggles in their role as fathers. They also described their desire to break the cycle of abuse, to provide a better childhood for their children and to seek healing of their trauma. The findings suggested that fatherhood can be a transformational process and presents many opportunities for restoring the self.

\section{References}

Babcock Fenerci, R. L., \& DePrince, A. P. (2018). Intergenerational transmission of trauma: Maternal trauma-related cognitions and toddler symptoms. Child Maltreatment, 23, 126-136. https://doi.org/10.1177/1077559517737376.

Ball, J. D. (2009). Intergenerational transmission of abuse of incarcerated fathers: A study of the measurement of abuse. Journal of Family Issues, 30, 371-390. https:// doi.org/10.1177/0192513X08326327.

Barton, S., Gonzalez, R., \& Tomilson, P. (2010). Therapeutic residential care for children and young people: An attachment and trauma-informed model for practice. London, UK: Jessica Kingsley Publishers.

Berthelot, N., Paccalet, T., Gilbert, E., Moreau, I., Mérette, C., Gingras, N., ... Maziade, M. (2015). Childhood abuse and neglect may induce deficits in cognitive precursors of psychosis in high-risk children. Journal of Psychiatry and Neuroscience, 40, 336-343. https://doi.org/10.1503/jpn.140211.

Bowlby, J. (1973). Separation: Anxiety and anger. New York, NY: Basic Books.

Bowlby, J. (1982). (2nd ed.). Attachment and loss: Attachment Volume I. New York, NY: Basic Books.

Bretherton, I. (1990). Communication patterns, internal working models, and the intergenerational transmission of attachment relationships. Infant Mental Health Journal, 11, 237-252. https://doi.org/10.1002/1097-0355(199023)11:3 < 237::AID-IMHJ2280110306 > 3.0.CO;2-X. 
Chouliara, Z., Karatzias, T., Scott-Brien, G., Macdonald, A., MacArthur, J., \& Frazer, N. (2011). Talking therapy services for adult survivors of childhood sexual abuse (CSA) in Scotland: Perspectives of service users and professionals. Journal of Child Sexual Abuse, 20, 128-156. https://doi.org/10.1080/10538712.2011.554340.

Cohen, T. (1995). Motherhood among incest survivors. Child Abuse \& Neglect, 19, 1423-1429. https://doi.org/10.1016/0145-2134(96)80760-5.

Cook, W. L. (2000). Understanding attachment security in family context. Journal of Personality and Social Psychology, 78, 285-294. https://doi.org/10.1037/00223514.78 .2 .285

Crittenden, P. M. (2006). A dynamic-maturational model of attachment. The Australian and New Zealand Journal of Family Therapy, 27, 105-116. https://doi.org/10. 1002/j.1467-8438.2006.tb00704.x.

Crome, S. (2006). Male survivors of sexual assault and rape (ACSSA Wrap No. 2.). Melbourne, VIC: Australian Centre for the Study of Sexual Assault.

Denov, M. S. (2004). The long-term effects of child sexual abuse by female perpetrators: A qualitative study of male and female victims. Journal of Interpersonal Violence, 19, 1137-1156. https://doi.org/10.1177/0886260504269093.

Dorahy, M. J., \& Clearwater, K. (2012). Shame and guilt in men exposed to childhood sexual abuse: A qualitative investigation. Journal of Child Sexual Abuse, 21, 155-175. https://doi.org/10.1080/10538712.2012.659803.

Easton, S. D. (2014). Masculine norms, disclosure, and childhood adversities predict long-term mental distress among men with histories of child sexual abuse. Child Abuse \& Neglect, 38, 243-251. https://doi.org/10.1016/j.chiabu.2013.08.020.

Edwards, K., Kearns, M. C., Calhoun, K. S., \& Gidycz, C. A. (2009). College women's reactions to sexual assault research participation: Is it distressing? Psychology of Women Quarterly, 33, 225-234. https://doi.org/10.1111/j.1471-6402.2009.01492.x.

Elliott, A. N., \& Carnes, C. N. (2001). Reactions of nonoffending parents to the sexual abuse of their child: A review of the literature. Child Maltreatment, 6, 314-331. https://doi.org/10.1177/1077559501006004005.

Etherington, K. (1995). Adult male survivors of childhood sexual abuse. Counselling Psychology Quarterly, 8, 233-241. https://doi.org/10.1080/09515079508256342.

Fitzgerald, M. M., Shipman, K. L., Jackson, J. L., McMahon, R. J., \& Hanley, H. M. (2005). Perceptions of parenting versus parent-child interactions among incest survivors. Child Abuse \& Neglect, 29, 661-681. https://doi.org/10.1016/j.chiabu.2004.10.012.

Fonagy, P., Gergely, G., Jurist, E. L., \& Target, M. (2002). Affect regulation, mentalization and the development of the self. New York, NY: Other Press.

Gill, M., \& Tutty, L. (1999). Male survivors of childhood sexual abuse: A qualitative study and issues for clinical consideration. Journal of Child Sexual Abuse, 7, 19-33. https://doi.org/10.1300/J070v07n03_02.

Hazen, N. L., McFarland, L., Jacobvitz, D., \& Boyd-Soisson, E. (2010). Fathers' frightening behaviours and sensitivity with infants: Relations with fathers' attachment representations, father-infant attachment and children's later outcomes. Early Child Development and Care, 180, 51-69. https://doi.org/10.1080/ 03004430903414703.

Hillberg, T., Hamilton-Giachritsis, C., \& Dixon, L. (2011). Review of meta-analyses on the association between child sexual abuse and adult mental health difficulties. Trauma, Violence \& Abuse, 12, 38-49. https://doi.org/10.1177/1524838010386812.

Joseph, S., \& Linley, P. A. (2005). Positive adjustment to threatening events: An organismic valuing theory of growth through adversity. Review of General Psychology, 9, 262-280. https://doi.org/10.1037/1089-2680.9.3.262.

Kelly, K., Slade, A., \& Grienenberger, J. (2005). Maternal reflective functioning, mother-infant affective communication and infant attachment: Exploring the link between mental states and observed caregiving behaviour in the intergenerational transmission of attachment. Attachment \& Human Development, 7, $299-311$. https://doi.org/10.1080/14616730500245963.

Kia-Keating, M., Grossman, F. K., Sorsoli, L., \& Epstein, M. (2005). Containing and resisting masculinity: Narratives of renegotiation among resilient male survivors of childhood sexual abuse. Psychology of Men \& Masculinity, 6, 169-185. https://doi.org/10.1037/1524-9220.6.3.169.

Koren-Karie, N., Oppenheim, D., \& Getzler-Yosel, R. (2008). Mothers who were severely abused during childhood and their children talk about emotions: Coconstruction of narratives in light of maternal trauma. Infant Mental Health Journal, 25, 300-317. https://doi.org/10.1002/imhj.20007.

Lainsbury, D. (1999). Child is father to the man. A survivor of childhood sexual abuse speaks out. Midwifery Today With International Midwife, 51, 25-27.

Lisak, D. (1995). Integrating a critique of gender in the treatment of male survivors of childhood abuse. Psychotherapy Theory Research Practice Training, 32, 258-269. https://doi.org/10.1037/0033-3204.32.2.258.

Lisak, D. (2001). Male survivors of trauma. In G. R. Brooks, \& G. E. Good (Eds.). The new handbook of psychotherapy and counselling with men: A comprehensive guide to settings, problems and treatment approaches (pp. 263-278). San Francisco, CA: Jossey-Bass.

Lyons-Ruth, K., \& Block, D. (1996). The disturbed caregiving system: Relations among childhood trauma, maternal caregiving and infant affect and attachment. Infant Mental Health Journal, 17, 257-275 DOI: 10.1002/(SICI)1097-0355(199623)17:3 < 257::AID-IMHJ5 > 3.0.CO;2-L.

Lyons-Ruth, K., \& Spielman, E. (2004). Disorganized infant attachment strategies and helpless-fearful profiles of parenting: Integrating attachment research with clinical intervention. Infant Mental Health Journal, 25, 318-335. https://doi.org/10.1002/imhj.20008.

Madsen, S. A. (2009). Men's mental health: Fatherhood and psychotherapy. The Journal of Men's Studies, 17, 15-30. https://doi.org/10.3149/jms.1701.15.

Main, M., \& Hesse, E. (1990). Parents' unresolved traumatic experiences are related to infant disorganized attachment status: Is frightened and/or frightening parental behaviour the linking mechanism? In M. T. Greenberg, D. Cicchetti, \& E. M. Cummings (Eds.). Attachment in the preschool years: Theory, research, and intervention (pp. 161-182). Chicago, MA: University of Chicago Press.

Main, M., Hesse, E., \& Goldwyn, R. (2008). Studying differences in language usage in recounting attachment history: An introduction to the AAI. In H. Steele, \& M. Steele (Eds.). Clinical applications of the adult attachment interview (pp. 31-68). New York, NY: Guilford Press.

Main, M., Kaplan, N., \& Cassidy, J. (1985). Security in infancy, childhood, and adulthood: A move to the level of representation. Monographs of the Society for Research in Child Development, 50(1-2), 66-104. https://doi.org/10.2307/3333827.

Maker, A. H., \& Buttenheim, M. (2000). Parenting difficulties in sexual abuse survivors: A theoretical framework with dual psychodynamic and cognitive-behavioural strategies for intervention. Psychotherapy, 37, 159-170. https://doi.org/10.1037/h0087796.

Marsiglio, W., \& Hutchinson, S. (2002). Sex, men, and babies: Stories of awareness and responsibility. New York, NY: New York University Press.

McElvaney, R. (2015). Disclosure of child sexual abuse: Delays, non-disclosure and partial disclosure. What the research tells us and implications for practice. Child Abuse Review, 24, 159-169. https://doi.org/10.1002/car.2280.

Nelson, S. (2009). Care and support needs of men who survived childhood sexual abuse: Report of a qualitative research project. Edinburgh: The University of Edinburgh.

Newcombe, M. D., \& Locke, T. F. (2001). Intergenerational cycle of maltreatment: A popular concept obscured by methodological limitations. Child Abuse \& Neglect, 25, 1219-1240. https://doi.org/10.1016/S0145-2134(01)00267-8.

Paolucci, E. O., Genuis, M. L., \& Violato, C. (2001). A meta-analysis of the published research on the effects of child sexual abuse. The Journal of Psychology, 135, 17-36. https://doi.org/10.1080/00223980109603677.

Parry, S., \& Simpson, J. (2016). How do adult survivors of childhood sexual abuse experience formally delivered talking therapy? A systematic review. Journal of Child Sexual Abuse, 25, 793-812. https://doi.org/10.1080/10538712.2016.1208704.

Price-Robertson, R. (2012). Child sexual abuse, masculinity and fatherhood. Journal of Family Studies, 18, 130-142. https://doi.org/10.5172/jfs.2012.18.2-3.130.

Rapsey, C., Campbell, A., Clearwater, K., \& Patterson, T. (2017). Listening to the therapeutic needs of male survivors of childhood sexual abuse. Journal of Interpersonal Violence. https://doi.org/10.1177/0886260517701453.

Rogers, C. R. (1961). On becoming a person: A therapist view of psychotherapy. London: Constable.

Romano, E., Moorman, J., Ressel, M., \& Lyons, J. (2019). Men with childhood sexual abuse histories: Disclosure experiences and links with mental health. Child Abuse \& Neglect, 89, 212-224. https://doi.org/10.1016/j.chiabu.2018.12.010.

Sandberg, J. G., Feldhousen, E. B., \& Busby, D. N. (2012). The impact of childhood abuse on women's \& men's perceived parenting: Implications for practitioners. The American Journal of Family Therapy, 40, 74-91. https://doi.org/10.1080/01926187.2011.566827.

Sanderson, C. (2006). Counselling adult survivors of child sexual abuse (3rd ed.). London, UK: Jessica Kingsley Publishers.

Slade, A., \& Cohen, L. J. (1996). The process of parenting and the remembrance of things past. Infant Mental Health Journal, 17, 217-238. https://doi.org/10.1002/ (SICI)1097-0355(199623)17:3<217::AID-IMHJ3 > 3.0.CO;2-L.

Smith, J. A., Flowers, P., \& Larkin, M. (2012). Interpretative phenomenological analysis: Theory, method and research. London, UK: Sage. 
Solomon, J., \& George, C. (1996). Defining the caregiving system: Toward a theory of caregiving. Infant Mental Health Journal, 17, 183-197. https://doi.org/10.1002/ (SICI)1097-0355(199623)17:3<183::AID-IMHJ1 > 3.0.CO;2-Q.

Thomas, P. M. (2005). Dissociation and internal models of protection: Psychotherapy with child abuse survivors. Psychotherapy Theory Research Practice Training, 42 , 20-36. https://doi.org/10.1037/0033-3204.42.1.20.

Tremblay, C., Hébert, M., \& Piché, C. (1999). Coping strategies and social support as mediators of consequences in child sexual abuse victims. Child Abuse \& Neglect, 23, 929-946. https://doi.org/10.1016/S0145-2134(99)00056-3.

Trickett, P. K., Noll, J. G., \& Putnam, F. W. (2011). The impact of sexual abuse on female development: Lessons from a multigenerational longitudinal research study. Development and Psychopathology, 23, 453-476. https://doi.org/10.1017/S0954579411000174.

Trickett, P. K., Reiffman, A., Horowitz, L. A., \& Putnam, F. W. (1997). Characteristics of sexual abuse trauma and prediction of developmental outcomes. In D. Cicchetti, \& S. Toth (Eds.). Rochester symposium on developmental psychopathology, vol VII: The effects of trauma on the developmental process (pp. 289-314). Rochester, NY: University of Rochester Press.

Walker, M. (1999). The inter-generational transmission of trauma: The effects of abuse on the survivor's relationship with their children and on the children themselves. European Journal of Psychotherapy Counselling \& Health, 2, 281-296. https://doi.org/10.1080/13642539908400813.

Wamser-Nanny, R. (2017). Maternal support following childhood sexual abuse: Links to parent-reported children's outcomes. Child Abuse \& Neglect, 67, 44-53. https:// doi.org/10.1016/j.chiabu.2017.02.023.

Wark, J., \& Vis, J. A. (2018). Effects of child sexual abuse on the parenting of male survivors. Trauma, Violence \& Abuse, 19(5), 499-511. https://doi.org/10.1177/ 1524838016673600

Zvara, B. J., Mills-Koonce, R., Carmody, K. A., Cox, M., \& The Family Life Project (2015). Childhood sexual trauma and subsequent parenting beliefs and behaviours. Child Abuse \& Neglect, 44, 87-97. https://doi.org/10.1016/j.chiabu.2015.01.012. 